\title{
Analysis of Volatile Compounds in Food and Cosmetic, Using the Purge and Trap Injector Coupled to a Gas Chromatograph with Photo Ionization Detector
}

\author{
Yunfang Zhao \\ R\&D Center of HongTa Tobacco Group Co., Ltd. \\ Yuxi 653100, Yunnan, China \\ School of Chemistry Science and Technology of Yunnan University \\ Kunming 650091, Yunnan, China \\ Sheming Lua (Corresponding author) \\ R\&D Center of HongTa Tobacco Group Co., Ltd. \\ Yuxi 653100, Yunnan, China \\ Tel: 86-877-296-8271Ｅ-mail: lushe@ustc.com \\ Chunbo Liu \\ R\&D Center of HongTa Tobacco Group Co., Ltd., Yuxi, Yunnan 653100, China \\ School of Chemistry and Biotechnology, Yunnan Nationalities University \\ Kunming 650031, Yunnan, China
}

Tel: 86-877-296-8271Ｅ-mail: lushe@ustc.com

Zhaoyu Meng \& Chaomin Ni

R\&D Center of HongTa Tobacco Group Co., Ltd.

Yuxi 653100, Yunnan, China

Qiu'e Cao

School of Chemistry Science and Technology of Yunnan University

Kunming 650091, Yunnan, China

Mingming Miao

R\&D Center of HongTa Tobacco Group Co., Ltd.

Yuxi 653100,Yunnan, China

\begin{abstract}
A method was developed to analyze volatile organic compounds (VOCs) in food, beverages and cosmetic samples. VOCs were isolated from a standard solution or samples using a purge-and-trap (PT) system and identified and quantified by a gas chromatograph with Photo Ionization Detector (GC-PID). The experimental conditions were optimized and the performance of the system was evaluated. Linear calibration curves were obtained with correlation coefficients of at least 0.9981 . RSDs were less than $6 \%$. Detection limits, calculated for $5 \mathrm{ml}$ sample volume, ranged from $0.3056 \mathrm{ng} \mathrm{ml}^{-1}$ for toluene to $7.1373 \mathrm{ng} \mathrm{ml}^{-1}$ for propionaldehyde. The method was successfully applied to the quantitative analysis of food and cosmetic samples. Propionialdehyde and butyraldehyde were not found in food
\end{abstract}


samples. Benzene and toluene were not detected in wine samples. Acetone was detected in all samples, except two samples. The method is reliable and is used for routine monitoring in food, beverages and cosmetic.

Keywords: Food, Cosmetic, Purge and trap, GC-PID, Volatile organic compounds

\section{Introduction}

The unintentional presence of organic solvents in food, beverages and cosmetic may originate from a number of sources, including transfer from packaging materials, degradation or reaction of preservatives, heat or processing conditions or as environmental contaminants. One group of solvents which are often determined due to concerns over their toxicity, are known as the BTLCs solvents (benzene, toluene and low-molecular weight carbonyl compounds) (Roose, \& Brinkman, 1998, p.233). The compounds of interest must be separated from the matrix and concentrated in order to reach the levels necessary for the methods and detectors used.

A wide number of techniques have been described in the literature for this purpose, including classical solvent extraction (Nicholson, Bursill, \& Couche, 1985, pp.221-223) and variations of the same, such as simultaneous distillation-extraction (SDE) (Rocha, Delgadillo, \& Correia, 1996, pp.865-871) and solid phase micro-extraction (SPME) (Gomez-Ariza, Garcia-Barrera, Lorenzo, \& Beltran, 2006, pp.133-140; Carasek, Cudjoe, \& Pawliszyn, 2007, p.10; Cardeal, \& Marriott, 2009, pp.747-750), in attempt to reduce the time needed and the volumes of organic solvent required. Headspace analysis (HS) (Bicchi, Cordero, Liberto, Sgorbini, \& Rubiolo, 2008, pp.221-233) and purge-and-trap (PT) (Huybrechts, Dewulf, Moerman, \& Langenhove, 2000, p.367; Preter, Staeyen, Esser, Rutgeerts, \& Verbeke, 2009, p.1477) techniques are commonly used for volatile organic compounds (VOCs) analysis in liquid samples. In the former, a part or all of the headspace gas is introduced into the separation column, which can be at low oven temperatures, being the "cryogenic oven-trapping (COT)" (Bicchi et al., 2008, pp.221-233). With PT, the target analytes are purged out of the sample by a gas-flow and subsequently trapped prior to analysis using either cryogenic (Schall, Laturnus, \& Heumann, 1994, pp.1315-1318; Miermans, van der Velde, \& Frintrop, 2000, pp.39-40; Chen, \& Her, 2001, pp229-230) or sorbent traps (Nicholson et al., 1985, pp.221-223; Silgoner, Rosenberg, \& Grasserbauer, 1997, pp.259-265; Gerbersmann, Lobinski, \& Adams, 1995, pp.93-95; Allonier, Khalanski, Bermond, \& Camel, 2000, p.467; Zygmunt, 1996, pp.157-160; Bicchi, Cordero, Liberto, Rubiolo, Sgorbini, \& Sandra, 2007, pp.137-140).

Comparisons of the different methods for treating samples for volatile organic compound determination can be consulted in the bibliography (Preter, Staeyen, Esser, Rutgeerts, \& Verbeke, 2009, p.1477; Golfinopoulos, Lekkas, \& Nikolaou, 2001, pp.275-276). Due to its high degree of sensitivity, purge-and-trap still remains the most frequently used pre-concentration system for VOCs in liquid samples when gas chromatography is used, although to the best of our knowledge, few reports have been published on VOC determination using Photo Ionization Detector (PID) as a detection method in PT-GC.

In PID, the analytes eluted from the GC column flows through the detector's ionizing chamber where high-energy ultraviolet light continuously irradiates the analytes. The UV lamp produces radiation in the UV spectrum, typically $10.0 \mathrm{eV}$ and $10.6 \mathrm{eV}$. The UV light's energy level determines the detection selectivity for ionizable components. Compounds with lower ionization potentials than the irradiation energy become ionized. Polarizing voltage accelerates ions onto a collector. The collected ions produce current proportional to the compound mass. The GC's electrometer amplifies and measures the ion current. After being detected, ions compose primary gas anew. So, PID is non-destructive.

In this study, procedures for the determination of seven volatile organic compounds, including benzene, toluene, aldehyde, propionaldehyde, acetone, butyraldehyde and butanone, in food, beverages and cosmetic samples, using PID as detection method in PT-GC are discussed. The method is rapid and involves minimal sample treatment.

\section{Experimental}

\subsection{Chemicals}

Benzene, toluene, aldehyde, propionaldehyde, acetone, butyraldehyde and butanone (except aldehyde, all $>98 \%$ purity) were obtained from CHEM SERVICE (WEST CHESTER, PA). All solvents were of analytical-reagent grade or better, and used as received. Their boiling points are between 20.8 and $110.8{ }^{\circ} \mathrm{C}$, as shown in Table 1 . Standard solutions of $60-2400 \mu \mathrm{g} \mathrm{ml}^{-1}$ of each compound were prepared in deionized water of analytical-reagent grade and stored in the dark at $4{ }^{\circ} \mathrm{C}$. Working standard solutions were prepared daily by diluting the standard solutions with deionized water obtained by using a Milli-Q water purification system (Millipore, Bedford, MA, USA) and also stored at $4{ }^{\circ} \mathrm{C}$ in the refrigerator.

\subsection{Apparatus and instrumental conditions}

Instrumental analysis was performed on an OI 4660 sample concentrator from OI Analytical, coupled to an Agilent Technologies $6890 \mathrm{~N}$ gas chromatograph equipped with a Photo Ionization Detector (PID) from OI Analytical.

The purging vessel was a $5 \mathrm{ml}$ glass U-tube with frit sparger 0.5 inch top fit. This was rinsed three times with the 
sample before each experiment, and further rinsed three times with deionized water after each analysis. The purge vessel was thermo-stated by using a lab-made system. A classic PT operating process was applied, including the three main steps: sample purging, analyte desorption and baking. Analytes were purged out from $5 \mathrm{ml}$ of aqueous solution with a nitrogen flow-rate of $40 \mathrm{ml} \mathrm{min}{ }^{-1}$ and carried to a trap column $(30.5 \mathrm{~cm} \times 0.312 \mathrm{~cm}$ o.d.) packed with Tenax GC, silica gel and activated carbon. The purge-and-trap system includes a moisture control module (MCM). The volatile organic compounds were desorbed from the trap, after being concentrated, by opening the valves at $190{ }^{\circ} \mathrm{C}$ for $0.5 \mathrm{~min}$. During the desorption step, the carrier gas was drawn through the trap in the opposite direction to the purge flow onto the column, in order to minimize band broadening at the beginning of the chromatographic column. Once the analytes had been desorbed, the trap was cleaned at $210{ }^{\circ} \mathrm{C}$ for $10 \mathrm{~min}$, to avoid possible memory effects of the tailing compounds. The purge-and-trap system was directly coupled to the gas chromatograph in a direct split interface (DSI) configuration, set at $150{ }^{\circ} \mathrm{C}$ in order to avoid analytes condensation during the analysis. The end of the transfer line was directly inserted into the split injector of the GC. An Agilent $6890 \mathrm{~N}$ gas chromatograph was directly coupled by a transfer line to PID. The instrumental conditions are summarized in Table 2.

A triturator (PHILIPS) was used for some food samples.

\subsection{Sampling}

Six food samples, two alcohol samples, two beer samples and ten cosmetic samples of different trademarks were obtained from supermarket. All samples were kept at $4{ }^{\circ} \mathrm{C}$ before their analysis.

\subsection{Sample treatment and recovery assays}

Triturating sample treatment was required for solid samples, and in case of the high BTLCs content in some liquid samples, a 1: 25 dilution was required. Two drops of silicone antifoam were added to $20 \mathrm{ml}$ of beer to avoid the foam normally produced during the purge step. Besides, the solid samples were centrifugated prior to the addition of the antifoam agent.

Sample volumes of $5 \mathrm{ml}$ (the maximum volume permitted in the purging vessel) were submitted to the optimized procedure.

All samples were spiked by adding from 0.866 to $2340 \mathrm{ng}$ of the volatile organic compounds, depending on the compound, to $5 \mathrm{ml}$ of sample.

\section{Results and discussion}

\subsection{Optimization of the purge-and-trap conditions}

The parameters were varied in order to obtain the highest degree of sensitivity and the best repeatability for the compounds investigated. For this, standard solutions of the analytes at $200 \mu \mathrm{g} \mathrm{ml}^{-1}$ in deionized water were used. Evaluation of the purge-and-trap step was made for each compound by comparing peak areas obtained by either purge-and-trap injections under different experimental conditions. All experiments were carried out in triplicate. Care was taken to remain below the breakthrough volume of the trap for all the experiments. When purge flow is too low, quantitative purging is impossible, whereas if purge flows are too high, an ineffective removing of the water happens, and the trap gets blocked. Therefore, the purge gas flow-rate was set at $40 \mathrm{ml} \mathrm{min}^{-1}$ in accordance with the manufacturer's recommendations. A certain time is necessary to purge the compounds out of the sample, depending on the polarity and the boiling point of each analyte. The purge time was varied between 8 and 12 min with a desorption cycle of $0.5 \mathrm{~min}$ at $190{ }^{\circ} \mathrm{C}$ and a purge temperature of $22{ }^{\circ} \mathrm{C}$. Finally, a value of $11 \mathrm{~min}$ was chosen as optimal, since purging times higher than 9 min led to a slight decrease in the peak area of most of the studied compounds or had no significant effect. Indeed, very long purging times decreased the signals because the nitrogen itself causes stripping of the trapped analytes. The results obtained are shown in Fig. 1A for benzene, toluene, aldehyde, propionaldehyde, acetone, butyraldehyde and butanone (covering in this way the whole range of boiling points of the studied compounds), where the influence of the purge time on the extraction yield is expressed as peak area. As regards desorption time, it was varied between 0.5 and $2 \mathrm{~min}$, finally being fixed at $0.5 \mathrm{~min}$, which provided the highest peak areas for all the compounds (Fig. 1B). The chosen conditions for the purge-and-trap system are summarized Table 2.

\subsection{Chromatographic parameters}

Preliminary experiments were conducted to choose the temperature program that best allowed separation of the seven volatile organic compounds in the lowest possible time. The selected program temperature allowed elution of the 7 compounds between 6 and $15 \mathrm{~min}$, as shown by their respective retention times in Table 1. The chromatogram started at $40{ }^{\circ} \mathrm{C}$ before being increased to $80{ }^{\circ} \mathrm{C}$ which was maintained for $1 \mathrm{~min}$, and $2{ }^{\circ} \mathrm{C} \min ^{-1}$ ramp to $80{ }^{\circ} \mathrm{C} ; 5{ }^{\circ} \mathrm{C} \mathrm{min}^{-1}$ ramp to $150{ }^{\circ} \mathrm{C}$, and $10 \mathrm{~min}$ held at $150{ }^{\circ} \mathrm{C}$. Separation was carried out using a constant nitrogen flow rate of $1 \mathrm{ml} \mathrm{min}^{-1}$, since higher flow rates resulted in overlapping peaks and lower flow rates increased peak widths and hence analysis time. The injection temperature is the temperature of the compounds entering the analytical column after passing through the transfer line between the purge-and-trap system and the GC. This temperature therefore has to be higher or 
equal to $150{ }^{\circ} \mathrm{C}$.

After choosing the most suitable chromatographic parameters, the detector operating conditions were studied to obtain the highest sensitivity for the studied volatile organic compounds. The detector parameters investigated was make-up gas flow rate.

To select the optimum value for the nitrogen make-up gas flow that allows maximum sensitivity, the flow-rate was varied from 30 to $45 \mathrm{ml} \mathrm{min}^{-1}$. No signals were obtained for the studied compounds for $30 \mathrm{ml} \mathrm{min}^{-1}$ make-up flow rate. Maximum sensitivity was obtained at $35 \mathrm{ml} \mathrm{min}^{-1}$ in the case of the four most retained compounds, while the rest of the compounds provided a maximum signal at $40 \mathrm{ml} \mathrm{min}^{-1}$. The nitrogen make-up gas flow was therefore adjusted to $40 \mathrm{ml}$ $\min ^{-1}$.

Fig. 2 shows the chromatograms obtained for a standard mixture and a part of samples under the optimized conditions.

\subsection{Calibration, precision and detection limits}

For calibration, working standard solutions at five concentration levels were prepared and $5 \mathrm{ml}$ aliquots of each standard were purged and analyzed. Two replicates for each calibration level were made. Linear calibration curves were obtained for all the compounds in different concentration ranges, depending on the compound. Table 3 shows the characteristics of the calibration graphs used to quantify each compound, with the retention times indicated in Table 1 being the most sensitive in every case. Correlation coefficients showed a high degree of correlation between concentration and peak area for the studied compounds, ranging from 0.9948 for toluene to 0.9998 for butanone. Detection limits were calculated by using a signal-to-noise ratio of 3 for all the investigated compounds. The repeatability was calculated by using the relative standard deviation for 6 successive injections of a standard mixture and was in the range of $2.45-5.11 \%$ (RSD) as shown in Table 4 for food, along with the recovery (\%).

\subsection{Samples}

The developed method was used to analyze the 20 analytes in different samples and the results obtained appear in Table 5 .

\subsubsection{Food samples}

In Table 5.A, six food samples (Green tea, Sauce, Pickle, Vinegar, Spice and Cutlet) were detected. Propionaldehyde and butyraldehyde not were found in the six samples. Acetone is used for solvent and it is produced via zymolysis. So it was detected in all samples. Benzene was detected in the only one food sample. Aldehyde is a material used in the process of manufacturing pickle, spice and so on. Aldehyde was found in four samples other than green tea and cutlet.

\subsubsection{Wine and beer}

In wine samples, as can be seen in Table 5.B, benzene and toluene were not detected in any samples. Aldehyde and acetone were found in all analyzed samples. The content of the substances analyzed in this study were found higher in white wine than in beer. This is why white wine is more harmful than beer to body.

\subsubsection{Cosmetic samples (Skin-care and Cleaning)}

In cosmetic, acetone and toluene were almost detected in samples. One of the cosmetics analyzed has aldehyde. As can be seen in Table 5.C, acetone was detected in all samples, except two samples. Toluene is a material that helps manufacture medicament and is used as solvent. So it was found in most samples. Propionaldehyde was found only in Skin-care cosmetic samples (Oil-control emulsion, Moisturizing emulsion and Hand cream). It is because propionaldehyde often is used for antiaging solvent.

From the Table 5, aldehyde, acetone and toluene were detected in most samples. Because aldehyde can be used as antiseptic, while acetone and toluene are generally used as solvent. Benzene was detected in few samples since it is forbidden to use.

\section{Conclusions}

The results of this study allow us to propose PT-GC-PID as an ideal technique for VOC analysis of spirits, due to its high resolution separation power, precise analytical measurement, low detection limit and enhanced sensitivity, all of which are invaluable to the study of the complexity of the present sample analyses. The renewed interest in research and development of PT is one of the consequences of the dramatically increasing demand for analyses (in particular for VOC's control purposes) over the last decade. It is also due to the ever-increasing importance of the volatile fraction, in particular in the food field. The pressing demand for innovative analytical approaches to deal with the problem that PT is not applicable to nonvolatile compounds. Nevertheless, much research effort is still required to develop reliable new approaches that will facilitate quantitative analysis and reduce sampling time, as well as to find materials that can extend the fields of application of PT technique. 


\section{Acknowledgements}

This research was financially supported by R\&D Center of HongTa Tobacco Group Co., Ltd. Yunfang Zhao acknowledges R\&D Center of HongTa Tobacco Group Co., Ltd. The authors would like to thank Mr. Lu and Mr. Liu for their technical assistance.

\section{References}

Allonier, A., Khalanski, M., Bermond, A., \& Camel, V. (2000). Determination of trihalomethanes in chlorinated sea water samples using a purge-and-trap system coupled to gas chromatography. Talanta, 51, 467.

Bicchi, C., Cordero, C., Liberto, E., Rubiolo, P., Sgorbini, B., \& Sandra, P. (2007). Sorptive tape extraction in the analysis of the volatile fraction emitted from biological solid matrices. Journal of Chromatography A, 1148(2), 137-140.

Bicchi, C., Cordero, C., Liberto, E., Sgorbini, B., \& Rubiolo, P. (2008). Headspace sampling of the volatile fraction of vegetable matrices. Journal of Chromatography A, 1184, 221-233.

Carasek, E., Cudjoe, E., \& Pawliszyn, J. (2007). Fast and sensitive method to determine chloroanisoles in cork using an internally cooled solid-phase microextraction fiber. Journal of Chromatography A, 1138(1-2), 10.

Chen, T., \& Her, G. (2001). On-line monitoring of trihalomethanes in drinking water using continuous-flow purge and cryofocusing gas chromatography-mass spectrometry. Journal of Chromatography A, 927, 229-230.

Cardeal, Z., \& Marriott, P. (2009). Comprehensive two-dimensional gas chromatography-mass spectrometry analysis and comparison of volatile organic compounds in Brazilian cachaça and selected spirits. Food Chemistry, 112, 747-750.

De Preter, V., Van Staeyen, G., Esser, D., Rutgeerts, P., \& Verbeke, K. (2009). Development of a screening method to determine the pattern of fermentation metabolites in faecal samples using on-line purge-and-trap gas chromatographic-mass spectrometric analysis. Journal of Chromatography A, 1216, 1477.

Gerbersmann, C., Lobinski, R., \& Adams, F.C. (1995). Determination of volatile sulfur compounds in water samples, beer and coffee with purge and trap gas chromatography-microwave-induced plasma atomic emission spectrometry. Analytica Chimica Acta, 316(1), 93-95.

Golfinopoulos, S.K., Lekkas, T.D., \& Nikolaou, A.D. (2001). Comparison of methods for determination of volatile organic compounds in drinking water. Chemosphere, 45, 275-276.

Gómez-Ariza, J.L., García-Barrera, T., Lorenzo, F. \& Beltrán, R. (2006). Use of multiple headspace solid-phase microextraction and pervaporation for the determination of off-flavours in wine. Journal of Chromatography A, 1112, 133-140.

Huybrechts,T., Dewulf, J., Moerman, O.,\& Langenhove, H.V. (2000). Evaluation of purge-and-trap-high-resolution gas chromatography-mass spectrometry for the determination of 27 volatile organic compounds in marine water at the ng $1^{-1}$ concentration level. Journal of Chromatography A, 893, 367.

Miermans, C.J.H., van der Velde, L.E., \& Frintrop, P.C.M. (2000). Analysis of volatile organic compounds, using the purge and trap injector coupled to a gas chromatograph/ion-trap mass spectrometer: Review of the results in Dutch surface water of the Rhine, Meuse, Northern Delta Area and Westerscheldt, over the period 1992-1997. Chemosphere, 40, 39-40.

Nicholson, B.C., Bursill, D.B., \& Couche, D.J. (1985). Rapid method for the analysis of trihalomethanes in water. Journal of Chromatography A, 325, 221-223.

Roose,P, \& Brinkman, U. A.Th.(1998). Determination of volatile organic compounds in marine biota. Journal of Chromatography A, 799, 233.

Rocha, S., Delgadillo, I., \& Correia, A. J. F. (1996). GC-MS study of volatiles of normal and microbiologically attacked cork from Quercus suber L. Journal of Agricultural and Food Chemistry, 44(3), 865-871.

Schall, C., Laturnus, F., \& Heumann, K.G. (1994). Biogenic volatile organoiodine and organobromine compounds released from polar macroalgae. Chemosphere, 28(7),1315-1318.

Silgoner, I., Rosenberg, E., \& Grasserbauer, M. (1997). Determination of volatile organic compounds in water by purgeand-trap gas chromatography coupled to atomic emission detection. Journal of Chromatography A, 768, 259-265.

Zygmunt, B. (1996). Determination of trihalomethanes in aqueous samples by means of a purge-and-trap system with on-sorbent focusing coupled to gas chromatography with electron-capture detection. Journal of Chromatography A, 725,157-160. 
Table 1. List of compounds

\begin{tabular}{cccc}
\hline Compound & Molecular & Boiling & Retention \\
& formula & point $\left({ }^{\circ} \mathrm{C}\right)$ & time (min) \\
\hline Aldehyde & $\mathrm{C}_{2} \mathrm{H}_{4} \mathrm{O}$ & 20.8 & 6.283 \\
Propionaldehyde & $\mathrm{C}_{3} \mathrm{H}_{6} \mathrm{O}$ & 48 & 7.256 \\
Acetone & $\mathrm{CH}_{3} \mathrm{COCH}_{3}$ & 56.48 & 7.666 \\
Butyraldehyde & $\mathrm{C}_{4} \mathrm{H}_{8} \mathrm{O}$ & 75.7 & 8.920 \\
Butanone & $\mathrm{CH}_{3} \mathrm{CH}_{2} \mathrm{COCH}_{3}$ & 79.6 & 9.554 \\
Benzene & $\mathrm{C}_{6} \mathrm{H}_{6}$ & 80.1 & 10.905 \\
Toluene & $\mathrm{C}_{6} \mathrm{H}_{5} \mathrm{CH}_{3}$ & 110.8 & 14.989 \\
\hline
\end{tabular}

Table 2. Experimental conditions of the PT-GC system

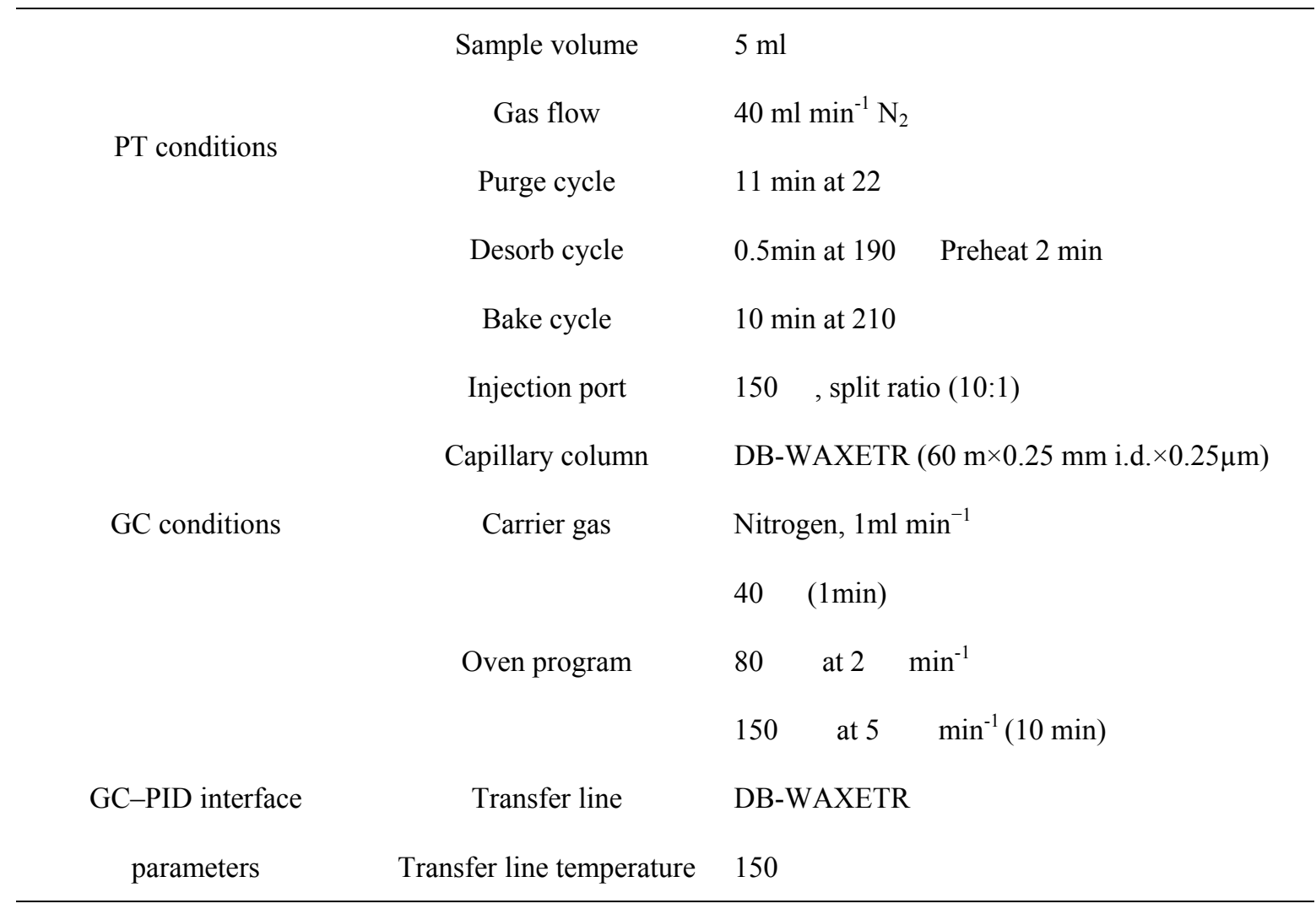


Table 3. The regression equation and relative coefficient of the method

\begin{tabular}{ccc}
\hline Compound & Regression equation & Relative coefficient \\
Aldehyde & $\mathrm{y}=10.0278 \mathrm{x}+14.3221$ & 0.9990 \\
Propionaldehyde & $\mathrm{y}=1.0135 \mathrm{x}-10.6905$ & 0.9997 \\
Acetone & $\mathrm{y}=0.2754 \mathrm{x}+19.6169$ & 0.9985 \\
Butyraldehyde & $\mathrm{y}=0.6155 \mathrm{x}-0.9066$ & 0.9993 \\
Butanone & $\mathrm{y}=0.2377 \mathrm{x}+5.0852$ & 0.9998 \\
Benzene & $\mathrm{y}=2.5072 \mathrm{x}-1.3130$ & 0.9981 \\
Toluene & $\mathrm{y}=2.6441 \mathrm{x}-.0993$ & 0.9948 \\
\hline
\end{tabular}

Table 4. The RSD, recovery and detection limits of the method to detected food

\begin{tabular}{cccccc}
\hline Compound & Added amount & Determined amount & Recovery & RSD & Detection limits (ng \\
& $(\mu \mathrm{g})$ & $(\mu \mathrm{g})$ & $(\%)$ & $(\%)$ & $\left.\mathrm{ml}^{-1}\right)$ \\
\hline Aldehyde & 2.34 & 2.293 & 98.00 & 4.44 & 1.404 \\
Propionaldehyde & 0.01594 & 0.01708 & 107.15 & 5.11 & 7.1373 \\
Acetone & 0.6304 & 0.6571 & 104.24 & 5.10 & 2.7077 \\
Butyraldehyde & 0.1602 & 0.159 & 99.25 & 3.41 & 6.0835 \\
Butanone & 0.6443 & 0.6492 & 100.76 & 5.10 & 6.5303 \\
Benzene & 0.03516 & 0.03581 & 101.85 & 2.45 & 0.9418 \\
Toluene & $8.66 \mathrm{e}-4$ & $7.0033 \mathrm{e}-4$ & 80.87 & 3.18 & 0.3056 \\
\hline
\end{tabular}


Table 5. Concentrations of the VOC in different matrices $\left(\mu \mathrm{g} \mathrm{ml}^{-1}\right)$. (A) Food samples, (B) wine samples, (C) cosmetic samples

\begin{tabular}{|c|c|c|c|c|c|c|c|}
\hline \multicolumn{8}{|c|}{ A } \\
\hline Compound & Aldehyde & Propionaldehyde & Acetone & Butyraldehyde & Butanone & Benzene & Toluene \\
\hline Green tea & ND & ND & 0.1029 & ND & ND & ND & ND \\
\hline Sauce & 77.84 & ND & 4.57 & ND & ND & ND & 0.059 \\
\hline Pickle & 104.04 & ND & 21.01 & ND & 15.15 & 1.05 & 0.072 \\
\hline Vinegar & 12.88 & ND & 12.71 & ND & ND & ND & 0.15 \\
\hline Spice & 39.31 & ND & 6.42 & ND & ND & ND & ND \\
\hline Cutlet & ND & ND & 3.53 & ND & 0.36 & ND & 0.05 \\
\hline \multicolumn{8}{|c|}{ B } \\
\hline White wine 1 & 23.77 & 2.18 & 6.43 & ND & 5.19 & ND & ND \\
\hline White wine 2 & 10.83 & ND & 1.07 & 0.81 & 0.89 & ND & ND \\
\hline Beer 1 & 7.02 & 0.027 & 0.13 & 0.0032 & ND & ND & ND \\
\hline Beer 2 & 2.82 & 0.56 & 0.82 & ND & 0.061 & ND & ND \\
\hline \multicolumn{8}{|c|}{$\mathrm{C}$} \\
\hline $\begin{array}{c}\text { Oil-control } \\
\text { emulsion }\end{array}$ & ND & 10.72 & ND & 76.94 & 55.9 & ND & 19.849 \\
\hline $\begin{array}{c}\text { Moisturizing } \\
\text { emulsion }\end{array}$ & ND & 73.013 & ND & 160.75 & ND & 153.53 & ND \\
\hline Hand cream & ND & 576.39 & 211.94 & 188.61 & ND & 325.56 & 11.47 \\
\hline $\begin{array}{l}\text { Whitening } \\
\text { sun block }\end{array}$ & ND & ND & ND & ND & ND & ND & 3.58 \\
\hline Bathed lotion & ND & ND & 15.60 & ND & ND & ND & 7.61 \\
\hline $\begin{array}{c}\text { Faced } \\
\text { cleansing }\end{array}$ & ND & ND & 6.48 & ND & ND & 0.61 & 0.71 \\
\hline $\begin{array}{c}\text { Hair-care } \\
\text { product }\end{array}$ & ND & ND & 7.22 & ND & ND & ND & 0.66 \\
\hline shampoo & ND & ND & 58.02 & ND & ND & ND & 3.86 \\
\hline Hand lotion & ND & ND & 42.05 & ND & ND & 0.71 & 1.44 \\
\hline $\begin{array}{l}\text { Constringency } \\
\text { water }\end{array}$ & 120.41 & ND & 13.55 & ND & 1.52 & ND & 0.17 \\
\hline
\end{tabular}

ND means non-detected. 

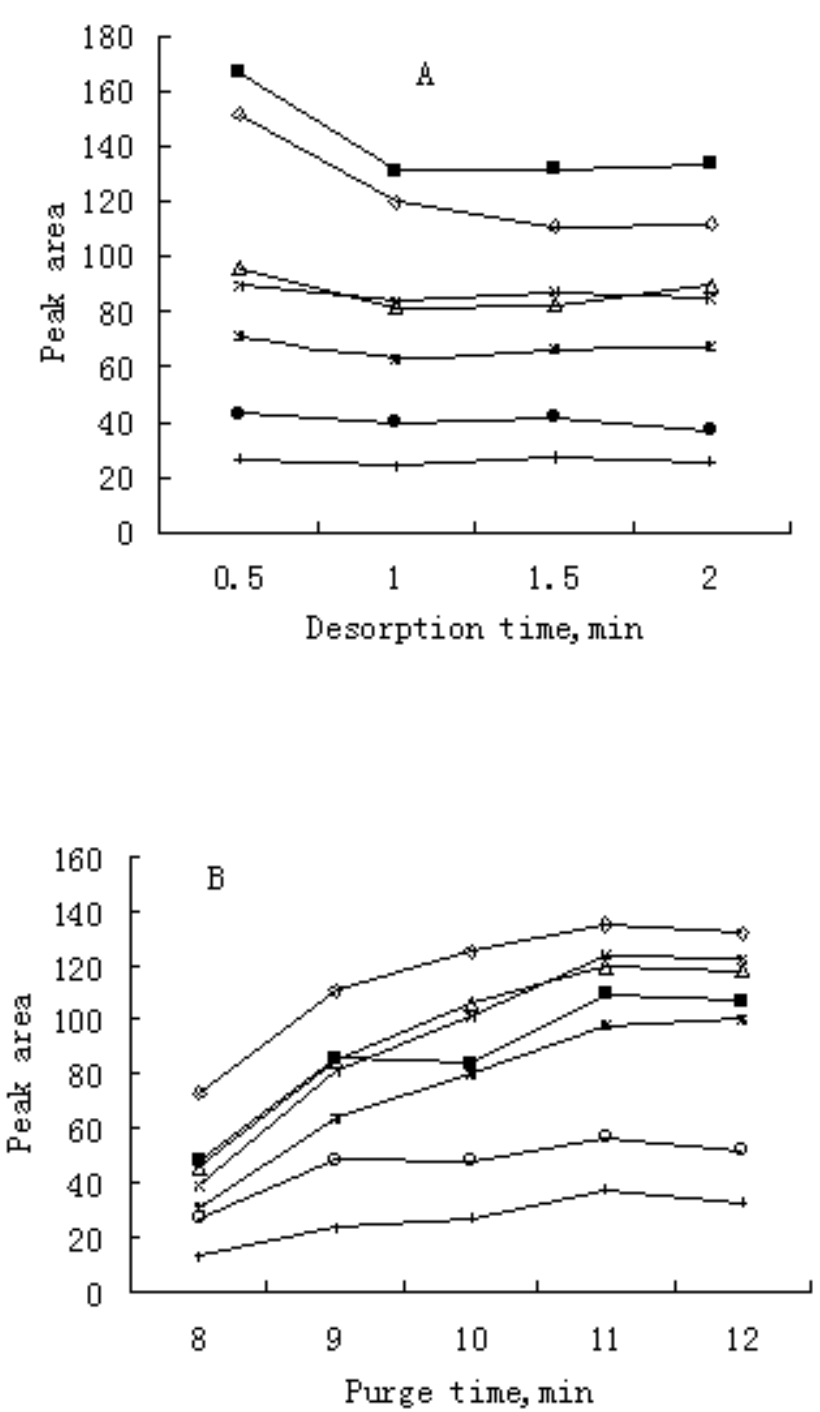

Figure 1. Effect of: (A) purge time; (B) desorption time; aldehyde $(\rightarrow)$,Propionaldehyde $(\rightarrow-)$, acetone $(\rightarrow)$, butyraldehyde $(\rightarrow)$, butanone $(\rightarrow)$, benzene $(\rightarrow-)$ toluene $(\longrightarrow)$ 


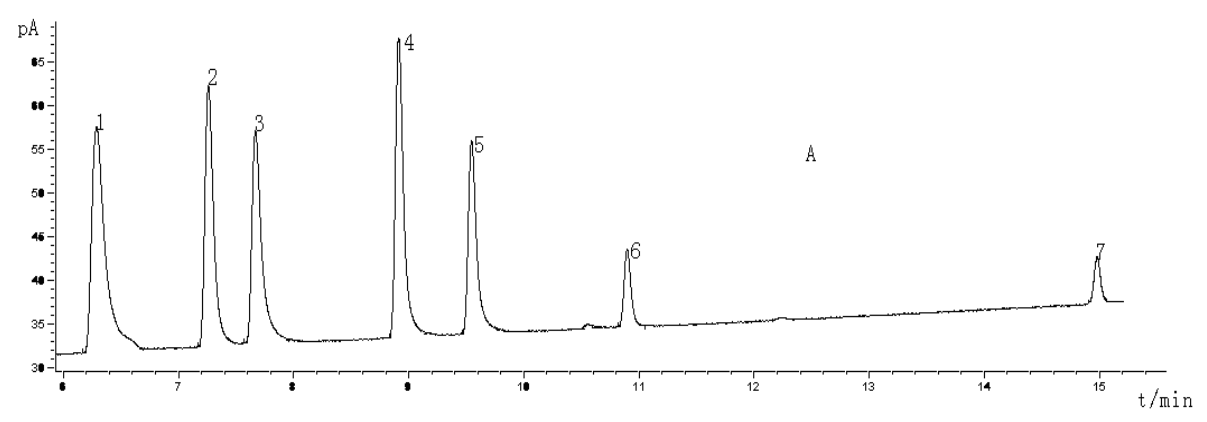

(A)

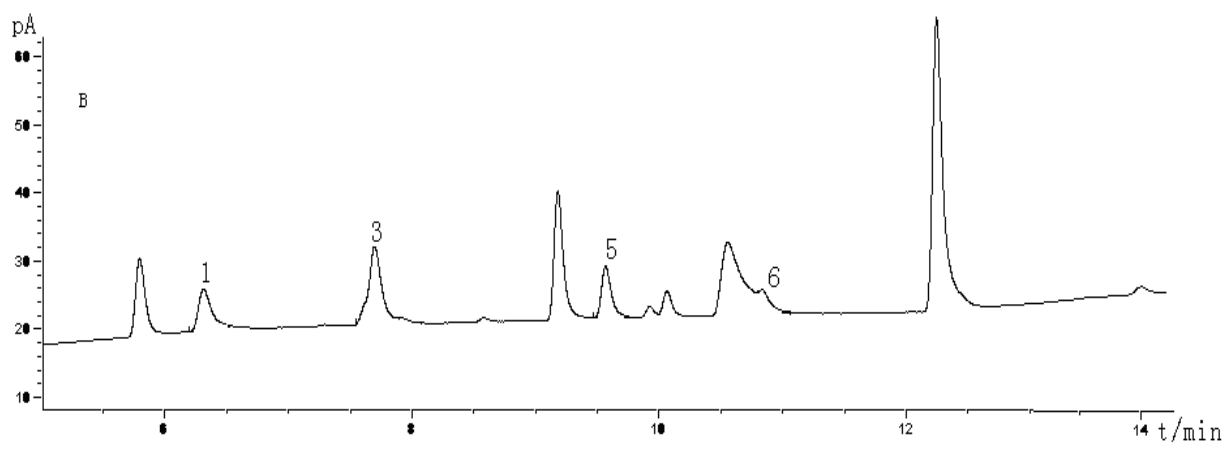

(B)

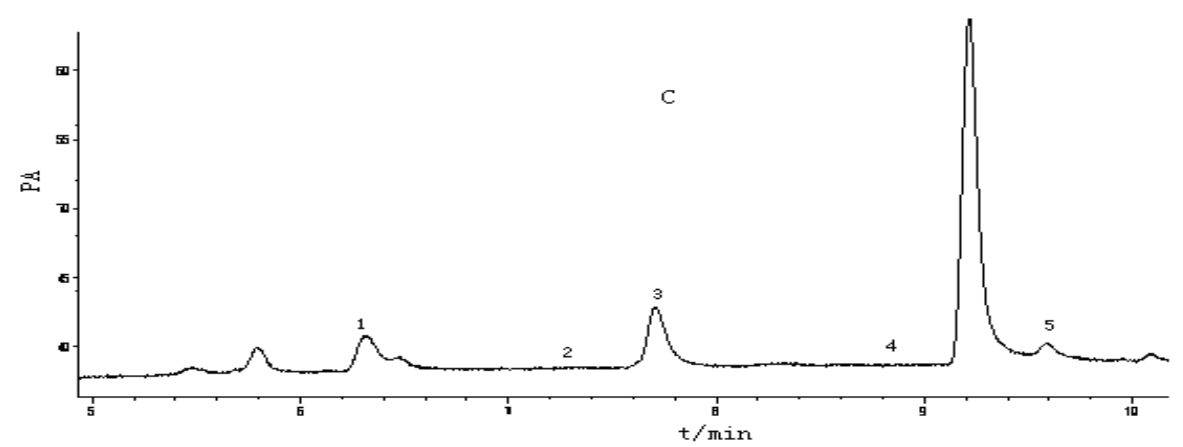

(C)

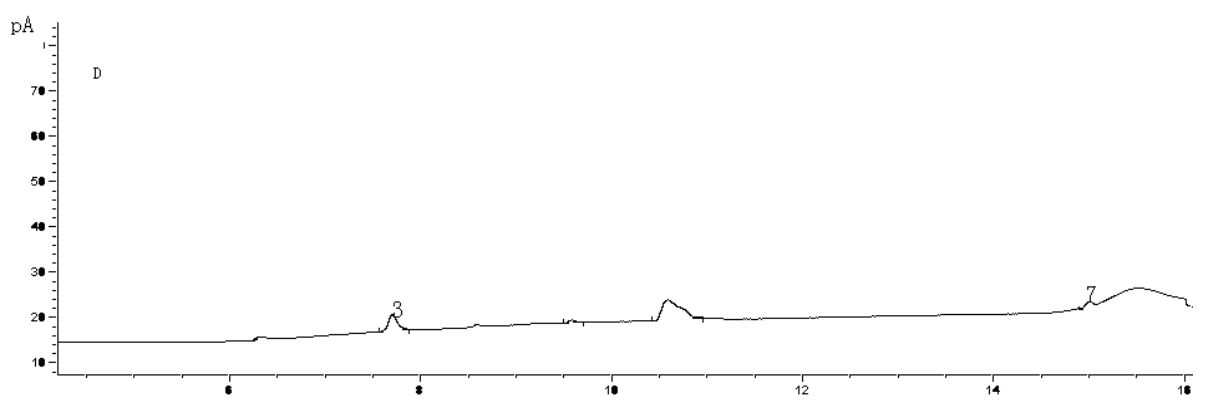

(D)

Figure 2. PT-GC-PID chromatograms from a standard mixture of the volatile organic compounds (A), one of the food samples chromatogram (B), one of the beer (C) and one of cosmetic samples (D) 